\title{
Should Autists Have Cultural Rights?
}

\author{
Bouke de Vries $^{1}$ (D)
}

Accepted: 5 October 2021 / Published online: 6 December 2021

(c) The Author(s) 2021, corrected publication 2022

\begin{abstract}
While several scholars have argued that the rise of the internet has allowed an autistic culture to emerge over the past two decades, the question of whether people with autism or, as some members of this group refer to themselves, 'autists', are legally entitled to their own cultural rights has not been investigated. This article fills part of this lacuna by considering whether such entitlements exist from the perspective of human rights law. I start by showing that, insofar as (some) autists have their own culture(s), they are likely to be entitled to cultural rights under existing human rights treaties, before arguing that the absence of evidence that their beliefs, values, and behaviors are significantly shaped by distinct social norms renders it unclear whether they do in fact have their own culture(s). However, I end by arguing that, in terms of autists' entitlements from a human rights perspective, little seems to depend on this.
\end{abstract}

Keywords Autism · Neurodiversity $\cdot$ Multiculturalism $\cdot$ Cultural rights $\cdot$ Right to particulate in culture life $\cdot$ Disabilities

\section{Introduction: Autism as a Culture Rather Than (Just) a Disability}

Autism, also known as Autism Spectrum Disorder or Autism Spectrum Condition, is seen by many as a disability, if not as a disorder. ${ }^{1}$ For example, it is listed in the fifth edition of the influential Diagnostic and Statistical Manual of mental disorders (DSM-5) as a disorder associated with 'persistent deficits in social communication and social interaction across multiple contexts' and with 'restricted, repetitive patterns of behavior, interests, or activities' (American Psychiatric Association, 2013).

\footnotetext{
1 The difference being that whereas disabilities hinder human functioning in some contexts but not others (which may vary depending upon whether environmental modifications are made), disorders undermine such functioning in (almost) all contexts. See Baron-Cohen (2017, p. 746).
}

Bouke de Vries

bouke.devries@umu.se

1 Department of Historical, Philosophical and Religious Studies, Umeå University, Umeå, Sweden 
However, not everyone accepts this characterization. In recent decades, a proportion of people with autism or, as they tend to refer to themselves, 'autistic people' or 'autists' (Jaarsma \& Welin, 2012, p. 21; Kenny et al., 2016), have protested what they regard as the medicalization of autism whereby autism is perceived as a deficit or pathology. For this group, which mainly comprises autists with a normal or above-average IQ who are often referred to as 'high-functioning autists' or as 'lowsupport-needs autists', ${ }^{23}$ autism, or at least moderate forms thereof, is simply a manifestation of neurological difference, ${ }^{4}$ which leads them to oppose attempts to find a cure for it. Indeed, not only has the medical paradigm surrounding autism been resisted in favor of one stressing neurological difference, there is a growing chorus of autists who maintain that they have their own culture (Davidson, 2008, pp. 791-795). While it may be difficult to see how individuals who are territorially dispersed and who struggle with face-to-face interaction could create their own culture, it has been argued that the rise of the internet has made this possible by allowing a form of communication that does not require physical proximity or the need to interpret body language, read faces, and maintain eye contact, which are activities that people on the autism spectrum tend to find challenging (Davidson, 2008).

In this article, my aim is to investigate whether (some) autists indeed have their own culture or cultures, and whether the existence of such culture(s) would generate entitlements to cultural rights under contemporary human rights law. Some scholars have argued that autistic culture(s) not only exist, but are entitled to cultural rights from a moral perspective. Drawing on work by political philosopher Will Kymlicka (1995), Pier Jaarsma and Stellan Welin argue, for instance, that autists ought to have cultural rights on the same grounds as ethnocultural minorities should have them, namely that their culture is being 'unfairly disadvantaged in the cultural market-place', which is understood to result from the 'economic and political decisions made by the majority of neurotypicals', i.e. by people without autism (Jaarsma \& Welin, 2012, p. 26)..$^{5}$ According to Jaarsma and Welin, the value of cultural membership is such that this disadvantage constitutes a 'significant inequality which, if not addressed [by offering group-differentiated rights], becomes a serious injustice' (Jaarsma \& Welin, 2012, p. 26).

I will not try to evaluate such ethical claims here. As was mentioned, my focus is on whether autistic communities are entitled to cultural rights from the perspective of human rights law as opposed to a moral perspective. (To see that these perspectives are not the same, notice that there are things that we morally ought to do, such as be kind to those who have been kind to us, or donate some of our money to charity if we can afford to do so, that are not legally required under human rights law;

\footnotetext{
${ }^{2}$ Since some autists find it ableist to describe autists as either 'high-functioning' or 'low-functioning' (Bottema-Beutel et al., 2021), I will use the terms 'low-support-needs autists' and 'high-support-needs autists' as well.

3 This group includes individuals with Asperger. See Jaarsma \& Welin (2012).

4 Which is why some of them refer to themselves as members of the 'Neurodiversity Movement'. See Jaarsma \& Welin (2012).

5 Notice that not everyone uses the term 'neurotypical' in this way and some prefer to use the term 'allistic' instead. In this article, I will use the former because it is more commonly used.
} 
at the same time, it is at least possible that there are human rights that cannot be morally justified, perhaps because they impose excessive costs on those who are to respect or honor them.) Addressing this issue is important given that, although no autistic community is to the best of my knowledge currently campaigning for cultural rights, ${ }^{6}$ this might well happen within the future as many (self-professed) cultural groups have been campaigning for such rights in recent decades, which include both minority cultures (Kymlicka, 1995), including Deaf cultures, and majority cultures (Orgad, 2015).

The remainder of this article is structured as follows. I start by showing that, insofar as autistic culture(s) exist, their members are likely to be entitled to their own cultural rights under existing human rights treaties ("Cultural rights for autists: Bases in human rights law" section). Next, I argue that the absence of evidence that the beliefs, values, and behaviors of autists are significantly shaped by distinct social norms renders it unclear whether they do in fact have their own culture(s) ("Do autists have their own culture(s)?" section). However, I end by arguing that, in terms of the practical implications from a human rights perspective, little seems to depend on this as the entitlements that they are likely to have under human rights law if they have their own culture(s) are (mostly) similar to the ones that they have if they lack their own culture(s) ("Does it legally matter whether autists have their own culture(s)?" section).

\section{Cultural Rights for Autists: Bases in Human Rights Law}

Let me begin by making good on the claim that if (some) autists have their own culture or cultures, they are likely to be entitled to distinct cultural rights under existing human rights law. By 'cultural rights', I here mean legal entitlements to the protection and promotion of a given culture by the state. Such rights are recognized in various international and regional human rights instruments. Particularly relevant is Article 15, paragraph 1(a) of the International Covenant on Economic, Social and Cultural Rights (ICESCR). Mirroring Article 27 of the Universal Declaration of Human Rights, this Article provides that.

The States Parties to the present Covenant recognize the right of everyone [...] to take part in cultural life [...] The steps to be taken by the States Parties to the present Covenant to achieve the full realization of this right shall include those necessary for the conservation, the development and the diffusion of science and culture.

At a regional level, rights to the enjoyment of culture and to cultural participation can be found in, e.g. Article 17(2) of the African Charter on Human and People's

\footnotetext{
${ }^{6}$ Note that simply believing that one has a particular culture does not presuppose that one wants cultural rights in the way that such rights are normally construed, namely as entitlements to forms of state support, protection, and accommodation that cannot be derived from standard packages of liberal-democratic rights. See Kymlicka, (1995).
} 
Rights; Article 14(1) of the Additional Protocol to the American Convention on Human Rights; Article 36 of the Arab Charter on Human Rights; and Article 32 of the Association of Southeast Asian Nations Human Rights Declaration. ${ }^{7}$

Exactly what do such rights entail? The clearest, and most elaborate, statement can be found in the General Comment on Article 15 paragraph 1(a) of the ICESCR (henceforth the General Comment), which is the authoritative interpretation of the 'right of everyone to take part in cultural life' by the Committee on Economic, Social and Cultural Rights.

The right to take part in cultural life can be characterized as a freedom. In order for this right to be ensured, it requires from the State party both abstention (i.e., noninterference with the exercise of cultural practices and with access to cultural goods and services) and positive action (ensuring preconditions for participation, facilitation and promotion of cultural life, and access to and preservation of cultural goods (UN Committee on Economic, Social and Cultural Rights, 2009, para. 6).

According to this passage, Article 15 of the ICESCR imposes both negative duties upon states not to prevent people from enjoying their cultures and positive duties to make sure that people can effectively participate in cultural life. As the General Comment goes on to specify, these latter duties entail obligations to 'take steps to prevent third parties from interfering in the right to take part in cultural life', as well as obligations to 'take appropriate legislative, administrative, judicial, budgetary, promotional and other measures aimed at the full realization of the right enshrined in article 15, paragraph 1 (a), of the Covenant' (UN Committee on Economic, Social and Cultural Rights, 2009, para. 48).

Now, by speaking of 'cultural life' simpliciter, Article 15 leaves open whether people should be able to participate in, and have access to, their own culture, or whether it is enough for them to be able to participate in, and have access to, some culture within society of which they need not be members. An example of the latter phenomenon would be when a state such as Canada did not grant cultural rights to the Quebecois and to its indigenous tribes, but simply made sure that members of these groups were able to participate in the cultural life of the Anglo-Canadians. However, subsequent specifications of the right to take part in cultural life within the General Comment suggest that people are indeed entitled to participate in the cultural life of their own communities and to have access to their own cultural activities. For example, it is said that, in order to comply with Article 15, states ought to be taking measures, including financial measures, to promote 'the exercise of the right of association for cultural and linguistic minorities for the development of their cultural and linguistic rights' (UN Committee on Economic, Social and Cultural Rights, 2009, para. 52; emphasis added) and to 'support minorities or other communities, including migrant communities, in their efforts to preserve their culture'

\footnotetext{
7 Although the European Convention on Human Rights does not recognize a similar right, it does mandate under Article 15(3) that state parties 'take measures, including technical aids' to provide persons with disabilities with access to 'cultural activities'.
} 
(UN Committee on Economic, Social and Cultural Rights, 2009, para. 52; emphasis added). Another relevant passage for our purposes, one that mirrors Article 30 of the Convention on the Rights of Persons with Disabilities of 2007, provides that 'in order to facilitate participation of persons with disabilities in cultural life, State Parties should, inter alia, recognize the right of these persons [...] to the recognition of their specific cultural and linguistic identity' (UN Committee on Economic, Social and Cultural Rights, 2009, para. 31; emphasis added).

Some may point out that autists are not territorially concentrated and grow up in cultures that might be called 'neurotypical'. By 'neurotypical cultures', I mean cultures of which the large majority of members are not on the autism spectrum, which include both majority cultures (e.g. those of Anglo-Canadians in Canada and Ethnic Germans in Germany) and minority cultures (e.g. the Quebecois and indigenous tribes in Canada, the Turkish minority, and Danish-speaking minority in Germany). Since (virtually) all autists are members of neurotypical cultures, it might be argued that, in order to honor their rights to their own cultural identity, it suffices for states to help ensure that they have access to their respective neurotypical cultures.

The reason why this seems mistaken is that the General Comment on Article 15 of the ICESCR explicitly mentions that the cultures of persons with disabilities that are to be recognized, protected, and supported include 'sign language and the culture of the deaf' (UN Committee on Economic, Social and Cultural Rights, 2009, para. 31). Since deaf people too are territorially dispersed and grow up within (wider) cultures of which the majority of members lack their disability, there are good grounds for thinking that, insofar as autists have their own culture(s), ensuring that they have access to neurotypical cultures is not enough to honor their cultural rights under existing human rights law in the same way that ensuring that Deaf communities have access to non-Deaf cultures does not suffice to honor theirs.

\section{Do Autists Have Their Own Culture(s)?}

But do autists have their own culture(s)? It is to this question that I wish to turn in this section.

In the late 1990s and early 2000s, some low-support-needs autists argued that an autistic culture was in the process of being established, a development that was considered to be facilitated by the rise of internet and the opportunities that this provided for autists to communicate without the difficulties that many of them experience with face-to-face contact, which may include problems interpreting body language, reading faces, maintaining eye contact, and responding to people without significant delay (cf. Davidson, 2008). As sociologist Judith Singer wrote in 1999, 'with our own communication medium, autistics are beginning to see ourselves not as blighted individuals, but as a different ethnicity' (Singer, 1999, p. 67). Or consider anthropologist Dawn Prince-Hughes' assertion in 2004 'that by telling and sharing stories, '[m] $\mathrm{m}] \mathrm{ch}$ like the deaf community, we autistics are building an emergent culture. We individuals, with our cultures of one, are building a culture of many' (Prince-Hughes, 2005, p. 7). 
Fast-forward 1.5 decades and we find that many scholars believe that such a culture has materialized. For example, in a chapter entitled 'Autism as Culture', music theorist Joseph Straus claims that the rise of the internet combined with the increase in autism diagnoses and the proliferation of literature, art, and music produced by autists has made it possible 'to conceive people with autism as a social group with a distinctive, shared culture' (Straus, 2013, p. 462). Or consider geographer Joyce Davidson who, drawing on a study of over forty autistic autobiographies, suggests that communication between low-support-needs autists is marked by 'distinctive autistic styles of communication' that ought to be interpreted as expressions of an 'autistic culture or form of life' (Davidson, 2008, p. 802). Indeed, the notion that (some) autists have their own culture(s) has gained such wide acceptance within parts of the academic community that a new scholarly journal, Ought (Ought: The Journal of Autistic Culture, n.d.), was founded recently whose self-proclaimed aim is 'to document autistic culture by publishing scholarly and creative works that examine and explore it'. 8

At the same time, however, there are scholars and commentators who reject the notion that there exist one or more autistic cultures. In a conference with the title 'The Culture of Autism', Judy Endow, author of several books on autism, tells how she has reluctantly arrived at the conclusion that there are no such cultures:

I hate to say that I have to conclude that autism is not a culture. I really do not like that all. I do not want that to be even close to the truth. Yet autism does not meet the current definitions and standards we use(Judy Endow's Culture of Autism Presentation, 2009).

This view is shared by the authors of The Teacch Approach to Autism Spectrum Disorder (Mesibov et al., 2004). While acknowledging that autism shapes how individuals think and what they feel and do (more on this shortly), they write that 'autism is of course not truly a culture; it is a developmental disability caused by neurological dysfunction’ (Mesibov et al., 2004, p. 19).

Which side is right? Assuming that it is not enough for people to merely believe that they have their own culture for said culture exist (which does not rule out, of course, that such beliefs are necessary; I remain non-committal on this), but that cultures must (also) have mind-independent features, answering this question requires us to examine the supposed objective building blocks of autistic cultures, i.e. the things out in the world that are necessary (and possibly sufficient) for autists to have one or more cultures. What follows is a list of the most widely mentioned, and it seems to me most promising, candidates within the scholarly literature, which cover both immaterial aspects of cultures (e.g. social, psychological, linguistic ones) and material aspects (e.g. artistic and literary productions).

\footnotetext{
${ }^{8}$ To be sure, most scholars who believe in the existence of a single autistic culture regard this culture as an heterogenous one. For example, the editors of Ought write that the journal recognizes 'that autistic culture is not monolithic: it is as varied as the autistic community itself'. See Ought: The Journal of Autistic Culture, (n.d.).
} 
Shared experiences: Autists share the experience of living in societies where most people are not on the spectrum. Since understanding the motives, emotions, and behaviors of neurotypical individuals is often difficult for them, many suffer feelings of alienation even if the extent to which they do varies depending upon where they find themselves on the spectrum. ${ }^{9}$ Another arduous experience that many face is having to cope with hyper-sensibilities and/or hypo-sensibilities in environments - e.g. schools, office spaces insofar as they are able to work - that are frequently poorly adjusted to their sensory profiles (Bogdashina \& Casanova, 2016).

Shared dispositions and behaviors: There are certain dispositions and behaviors that are relatively widespread among autistic individuals, such as an enhanced attentiveness to detail and a tendency to engage in repetitive behaviors such as stimming (Baron-Cohen, Simon et al., 2011).

Shared beliefs and commitments: As noted already, ${ }^{10}$ a proportion of mostly low-support-needs autists espouses the belief that autism ought to be accepted as a form of neurological difference as opposed to (just) a disability, let alone a disorder (Jaarsma \& Welin, 2012, p. 27). This belief is manifested in their claims that, rather than searching for a cure for autism, societies should simply become more accommodating of the needs of people who are not neurotypical (Jaarsma \& Welin, 2012, p. 27).

Shared vocabulary: Some low-support-needs autistic communities have their own vocabulary. Examples of used jargon within these communities include words such as Autie (an autistic person), Aspie (a person with Asperger), Neurotypical (a person who is not on the autism spectrum and does not have any neurological illnesses and disorders), and Curebie (someone who wants a cure for autism) (Stace, 2014).

Shared ways of communicating: In her aforementioned study of autistic autobiographies, Davidson finds that there are distinct autistic styles of communication that are characterized by e.g. their clarity and straightforwardness (Davidson, 2008, p. 796).

Shared interests: There are certain intellectual disciplines and pastimes in which many low-support-needs autists take an interest, such as mathematics, puzzle solving, science fiction, music, computers, and the memorization of favorite television shows and movies (Autism, PDD-NOS \& Asperger's Fact Sheets I Autistic Culture, n.d.; Straus, 2013, p. 473).

Literature: According to Joseph Straus, an 'autistic literary genre' has emerged in recent years as a result of the 'sheer number of autism memoirs now available', which, he believes, express 'a reliably authentic autistic world view' (Straus, 2013, p. 470).

\footnotetext{
${ }^{9}$ Consider, for instance, the following statement by Temple Grandin and Sean Barron, two autistic authors: 'that people with autism have to exist within a different culture on a day-to-day basis in order to survive- one that often blindly insists on conformity rather than respecting our cultural diversitymakes functioning in the world around us exceedingly difficult, often depressing and continually anxietyladen' (Grandin \& Barron, 2005, p. xvi).

${ }^{10}$ See the introduction.
} 
Artistic expressions: Straus also thinks that paintings by artists such as Jessica Park and Stephen Wiltshire, who has become world-famous for his cameralike cityscapes, are manifestations of an autistic culture (Straus, 2013, pp. 471473). In addition to being produced by autists, he believes that these artistic expressions are shaped by specific 'features of the autistic imagination', which include an above-average attention to detail, a love of repetition, and a disregard for social conventions (Straus, 2013, pp. 467-469).

Having looked at the most promising candidate-building blocks of autistic cultures, let us suppose for a moment that these various phenomena are indeed features of an autistic culture, or perhaps of several autistic cultures. In that case, it looks like that these cultures would merit state protection, accommodation, and support under Article 15 (1) of the ICESCR. To see this, it must be noted that the General Comment on this Article adopts a very broad conception of culture.

The Committee considers that culture, for the purpose of implementing article 15 (1) (a), encompasses, inter alia, ways of life, language, oral and written literature, music and song, non-verbal communication, religion or belief systems, rites and ceremonies, sport and games, methods of production or technology, natural and man-made environments, food, clothing and shelter and the arts, customs and traditions through which individuals, groups of individuals and communities express their humanity and the meaning they give to their existence, and build their world view representing their encounter with the external forces affecting their lives. Culture shapes and mirrors the values of well-being and the economic, social and political life of individuals, groups of individuals and communities (UN Committee on Economic, Social and Cultural Rights, 2009, para. 13). ${ }^{11}$

When we compare these claimed aspects of cultures to the ostensible building blocks of autistic cultures outlined earlier in this section, what we find is that various features that have been attributed to autistic communities are recognized by Article 15 (1) of the ICESCR as (possible) hallmarks of one or more cultures, including distinct forms of communication, distinct literature and music genres, and shared beliefs. The reason why I believe that it is nonetheless unclear as to whether (some)

\footnotetext{
11 This broad conception of 'culture' is mirrored in the interpretation of cultural human rights by Farida Shaheed (2010, para. 9), independent expert in the field of cultural rights, in her report to the Human Rights Council:

[C]ultural rights relate to a broad range of issues, such as expression and creation, including in diverse material and non-material forms of art; information and communication; language; identity and belonging to multiple, diverse and changing communities; development of specific world visions and the pursuit of specific ways of life; education and training; access, contribution and participation in cultural life; the conduct of cultural practices and access to tangible and intangible cultural heritage. Cultural rights protect the rights for each person, individually and in community with others, as well as groups of people, to develop and express their humanity, their world view and the meanings they give to their existence and their development through, inter alia, values, beliefs, convictions, languages, knowledge and the arts, institutions and ways of life. They may also be considered as protecting access to cultural heritage and resources that allow such identification and development processes to take place.
} 
autists have their own culture(s) is to do with fact that cultures are generally understood to contain social norms that influence to a substantial degree the beliefs, values, and behaviors of their members. This is not only reflected in common scholarly definitions of culture, ${ }^{12}$ but also in the observation of the General Comment that culture 'shapes and mirrors the values of well-being and the economic, social and political life of individuals' (UN Committee on Economic, Social and Cultural Rights, 2009 , para. 13). However, when we look at autistic communities, it is far from obvious that such norms are shaping their members' beliefs, values, and behaviors to a large enough extent to speak of the existence of one or more autistic cultures. The reason for this is not necessarily that people on the spectrum tend to be less sensitive to social norms and to the social expectations implied by such norms than their neurotypical counterparts. While some research supports this hypothesis (consider, for instance, a study by Keise Izuma et al. (2011), which found that, in the presence of an observer, neurotypical participants were more likely to donate to charity than autistic participants, as well as to donate more money, compared to a situation where they were unobserved, or a study by Yafai et al. (2014), which used a variation on the Ash conformity experiments to show that autistic children are more resistant to social pressure than their typically developing peers), other research has questioned this hypothesis (Gernsbacher et al., 2020; Jaswal \& Akhtar, 2019), or at least sought to qualify it (Cage et al., 2016; Van Hoorn et al., 2017). Rather, the reason is that, as some scholars have argued (Barnes \& McCabe, 2012, p. 263; Mesibov et al., 2004, p. 19), many of the regularities in the beliefs, values, and behaviors of autistic people can be explained equally well, if not better, by their neurological similarities and shared experiences in living in a society dominated by neurotypical individuals than by exposure to distinct autistic social norms. Indeed, for several of these regularities, such as many autists' above-average interests in detail; proclivities to engage in repetitive behavior; and straightforward communication styles, there are good grounds for thinking that such norms cannot be (largely) responsible for their existence given that they existed prior to the emergence of the mostly online communities that some now refer to as 'autistic cultures'.

Lest I be misunderstood, I am not suggesting that members of autistic communities are not influenced by fellow members in how they feel, think, and act. Such influences clearly exist as shown by, e.g. the emotional support and sense of belonging that many autists find in these communities (Jaarsma \& Welin, 2012, p. 26), as well as by the jargon that is used within some of them (although it bears emphasizing that this shared vocabulary is still miles apart from constituting a unique language as, e.g. Deaf communities have in various countries). ${ }^{13}$ What I am claiming is simply that there is currently inconclusive evidence that the regularities in the beliefs, values, and behaviors of members of autistic communities are produced predominantly by distinct social norms (as happens within neurotypical cultures) as opposed to a selection mechanism whereby those joining these communities already

\footnotetext{
12 Indeed, for some influential conceptions of culture such as Alan Patten's social lineage account, exposure to such norms is the central element of a culture. See Patten (2011).

13 See my comments earlier this section.
} 
largely share these features because of neurological and experiential similarities. If correct, then even though a growing number of people believes that one or more autistic cultures exist, and in some cases that they themselves are members of said culture(s), there is currently no good reason for thinking that they are right, assuming - as I have been doing - that for individuals to believe that they are members of a particular culture is not enough for said culture to exist. Instead, all that we have proof of is that there are (largely) online interest and support groups of autistic individuals that can be unequivocally said to constitute one or more cultures only in a very loose or metaphorical sense much like we sometimes speak of, e.g. the 'culture of science fiction fans, the culture of a particular college campus, and the culture of cancer survivors' (Barnes \& McCabe, 2012, p. 263), none of which is entitled to cultural rights under existing human rights instruments.

\section{Does It Legally Matter Whether Autists Have Their Own Culture(s)?}

Having argued that it is unclear whether autists have their own culture(s) as defined in existing human rights instruments, my contention in this final section is that, from the perspective of human rights law, not much hinges on this. To be more precise, I will argue that even if they do not, and consequently lack any claims to cultural rights qua autistic communities, ${ }^{14}$ this makes little difference in terms of what they are owed by states (and possibly in terms of what they are owed by non-state actors as well (cf. Shaheed, 2010, para. 20;47;51); for the purposes of this article, my focus is on states as they are the primary addressees of human rights treaties).

To vindicate this claim, we need to consider what respecting, protecting, and fulfilling the cultural rights of autistic communities would require. Since autistic communities are not territorially concentrated and exist mostly in the digital space (this is true even if there are events such as the annual Autism Pride Day where groups of autists meet in person) (Autistic Empire, n.d.), I take it that, insofar as they have their own culture(s), these should be understood first and foremost as online culture $(s)$. This has important implications for what members of autistic cultures would most likely be owed by states.

Regarding the negative duties of states to refrain from interfering 'with the exercise of cultural practices and with access to cultural goods and services' (UN Committee on Economic, Social and Cultural Rights, 2009, para. 6), what would seem to be required is that states do not interfere with the websites and fora of autistic communities, whether by blocking them or by censoring or manipulating their content. Such non-interference is vital for the survival and flourishing of these communities given that face-to-face communication among their members is often difficult to realize or simply very costly. One reason for this is that, as a territorially dispersed group, meeting in person may, and frequently does, pose significant logistical and organizational hurdles. However, even if they were a territorially concentrated

\footnotetext{
14 I say 'qua autistic communities' as the fact that they are simultaneously members of neurotypical cultures means that they would still be entitled to cultural rights as members of these cultures.
} 
group, the fact that many autists find face-to-face communication onerous, along with the fact that a large proportion has hyper sensibilities, means that such communication would remain unsuitable as the primary medium of communication.

What is pertinent for us is that, in order for such duties of non-interference to exist, it is not necessary for autists to have their own culture(s). They can instead be derived from non-cultural human rights such as the right to freedoms of opinion and expression, which is recognized under Article 19 of the International Covenant on Civil and Political Rights. This article provides that 'everyone shall have the right to hold opinions without interference' (para. 1), as well as 'the right to freedom of expression', including 'freedom to seek, receive and impart information and ideas of all kinds, regardless of frontiers, either orally, in writing or in print, in the form of art, or through any other media of his choice' (para. 2), which according to the General Comment on this Article by the Human Rights Committee includes 'electronic and internet-based modes of expression' (Human Rights Committee, 2011, para. 12). Given that the right to freedoms of opinion and expression is widely regarded as one of the most fundamental human rights, the support it lends to non-interference with the online life of autistic people and autistic communities (as well as that of non-autistic people and non-autistic communities) seems to be at least as strong as any support that cultural rights would provide.

I believe that similar conclusions can be drawn when it comes states' positive duties to protect and promote people's cultures as detailed in the General Comment on Article 21 of the International Covenant on Economic, Social and Cultural Rights. To recall, this comment instructs states to 'take steps to prevent third parties from interfering in the right to take part in cultural life' as well as 'take appropriate legislative, administrative, judicial, budgetary, promotional and other measures aimed at the full realization of the right enshrined in article 15, paragraph 1 (a), of the Covenant' (UN Committee on Economic, Social and Cultural Rights, 2009, para. 48). Applied to autistic culture(s) — assuming again arguendo that such cultures exist - two principal state obligations seem to flow from these provisions.

The first is that states ought to (try to) prevent third parties from unlawfully interfering with the online activities of autistic communities-e.g. by hacking their websites or fora-and hold those who are guilty of this to account. Doing so is critical for the functioning of these communities and, consequently, for the survival and flourishing of any autistic culture(s), because of the already mentioned fact that their members cannot easily meet and interact in person, or only at significant cost. The second obligation is that states should help to sustain any autistic cultures by ensuring that their members have affordable internet access or, insofar as budgetary constraints render this goal currently out of reach, by working progressively towards its realization. To see how this obligation arises, it should be noted that those who cannot afford internet access cannot participate in the online life of autistic communities, which is where any autistic cultures would exist for the most part (see my earlier comments). Furthermore, since many offline events are nowadays exclusively advertised online, there is a risk that autists without internet access will remain ignorant of any analogue autistic cultural events.

What is apposite for us is that, if I am right that these obligations are the principal positive obligations that any cultural human rights of autists would impose upon 
states, then like the aforementioned negative obligations, these obligations appear to exist irrespective of whether autists have cultures that entitle them to cultural human rights. As far as the obligation to protect their online expression and communication (as well as that of non-autistic people) is concerned, this duty can be derived from the human right to freedoms of expression and opinion as well, which does not only protect the right-holders from wrongful state interference, but also requires states to protect them from wrongful interferences by third parties. And while it might be less obvious how the obligation to help ensure that (autistic) people have affordable internet access can be derived from non-cultural human rights, I think that such derivations can be made as well.

One human right that seems to be capable of doingthe requisite grounding work is the right to health. Under Article 12 para. 1 of the international Covenant on Economic, Social and Cultural Rights, states are required to recognize everyone's right 'to the enjoyment of the highest attainable standard of physical and mental health'. To realize this right, there is a strong case to be made that internet access has become indispensable as it allows, among other things, those with chronic diseases to monitor their health through the use of wearable health technologies (e.g. Dinh-Le et al., 2019), as well as health services (e.g. medical advice) to be provided to people living in remote areas where there are few medical experts (e.g. Kumar et al., 2006).

Other non-cultural human rights whose fulfillment seems to require universal internet access within many countries concern the right to freedoms of opinion and expression and the right to freedom of association, which is recognized under Article 22 para. 1 of the International Covenant on Civil and Political Rights. As Merten Reglitz has argued (2020), the unprecedented ease with which the internet allows people to share their views with national and international audiences and to associate with others in order to campaign for various causes and to protest various (perceived) evils means that, ceteris paribus, the expressive and associative liberties of those with (unfettered) internet access will typically have a lot more value compared to those who lack (unfettered) internet access, which is problematic as it gives the former considerable power over the latter. However, if this is correct, then even if our civil and political rights can be equitably met in societies where the internet is not widely available through, e.g. 'letter writing, public events, and political party membership' (Reglitz, 2020), Reglitz seems right that this is no longer possible in societies where the internet has become available to a substantial proportion of the population but not universally.

\section{Concluding Remarks}

Whereas various scholars have argued that an autistic culture has emerged over the past two decades, the question of whether autists are legally entitled to their own cultural rights has not been investigated. In this article, I have filled part of this gap by considering whether such entitlements exist from the perspective of human rights law. I started by showing that, insofar as autists have their own culture(s), they are likely to be entitled to cultural rights under existing human rights instruments. Next, 
I argued that there is currently no evidence that autists' beliefs, values and behaviors (including their artistic and literary productions) are shaped by distinct social norms to such a degree as to allow us to say that they have their own culture(s). However, I ended by arguing that, in terms of the practical implications from a human rights perspective, little seems to hinge on this. There were three steps to this argument. First, I demonstrated that, if autistic cultures exist, they are online cultures for the most part. Second, I suggested that, in that case, honoring the cultural rights of autists will mainly require three things of states: not interfering with their online activities, protecting them from such interference by third parties, and helping to ensure that they have affordable internet access. Third, I showed that all these duties can be derived from the need to respect, protect, and fulfil various non-cultural human rights, including the right to freedoms of opinion and expression, the right to freedom of association, and the right to health. If correct, then although the abovementioned entitlements of autists would be on even stronger legal grounds if this group has its own culture(s), they do not depend upon the existence of such cultures.

To avoid confusion, I should end by noting that, to promote autists' social integration, there is a range of further measures that states might need to take-ones that complement the ones just mentioned-that do not depend upon this group having distinct cultural entitlements either. For example, De Vries (2021) has argued recently that autists should have legal rights to workspace accommodations of any hypersensitivities that they might have (e.g. ones to sound or to bright colors) as long as such accommodations can be made at reasonable cost, and that some of these accommodations ought to be made already at the construction and design stages of workspaces in order to address the needs of potential future autistic workers. In addition to this, it is imperative that schools teach students about the special needs and behaviors of people on the autism spectrum even if the precise nature of these needs will vary depending on where they find themselves on the spectrum, as well as about how certain common traits among autistic people-e.g. honesty, attention to detail, highly developed visual skills (Bennie, 2019; Grandin, 2009)—can enrich their own lives and that of others, apart from being an asset for particular types of businesses (Scott et al., 2017; Solomon, 2020).

Funding Open access funding provided by Umea University. My research is supported by an international postdoctoral fellowship (2018-00679) from the Swedish Research Council.

\section{Declarations}

Conflict of Interest The author declares no competing interests.

Open Access This article is licensed under a Creative Commons Attribution 4.0 International License, which permits use, sharing, adaptation, distribution and reproduction in any medium or format, as long as you give appropriate credit to the original author(s) and the source, provide a link to the Creative Commons licence, and indicate if changes were made. The images or other third party material in this article are included in the article's Creative Commons licence, unless indicated otherwise in a credit line to the material. If material is not included in the article's Creative Commons licence and your intended use is not permitted by statutory regulation or exceeds the permitted use, you will need to obtain permission 
directly from the copyright holder. To view a copy of this licence, visit http://creativecommons.org/licen ses/by/4.0/.

\section{References}

American Psychiatric Association. (2013). Diagnostic and Statistical Manual of Mental Disorders (DSM5). American Psychiatric Publishing.

Autism, PDD-NOS \& Asperger's fact sheets | autistic culture. (n.d.). Retrieved September 7, 2020, from https://www.autism-help.org/adults-autism-culture.htm

Autistic Empire. (n.d.). Autistic Pride. Autistic Empire. Retrieved September 13, 2020, from https://www. autisticempire.com/autistic-pride/

Barnes, R. E., \& McCabe, H. (2012). Should We Welcome a Cure for Autism? A Survey of the Arguments. Medicine, Health Care and Philosophy, 15(3), 255-269. https://doi.org/10.1007/ s11019-011-9339-7

Baron-Cohen, S. (2017). Editorial Perspective: Neurodiversity - a revolutionary concept for autism and psychiatry. Journal of Child Psychology and Psychiatry, and Allied Disciplines, 58(6), 744-747. https://doi.org/10.1111/jcpp.12703

Baron-Cohen, Simon, Ashwin, E., Ashwin, C., Tavassoli, T., \& Chakrabarti, B. (2011). The paradox of autism: Why does disability sometimes give rise to talent? In N. Kapur (Ed.), The Paradoxical Brain. Cambridge University Press.

Bennie, M. (2019, March 25). The Positives of Autism. Autism Awareness. https://autismawarenesscentre. com/the-positives-of-autism/

Bogdashina, O., \& Casanova, M. (2016). Sensory Perceptual Issues in Autism and Asperger Syndrome, Second Edition: Different Sensory Experiences - Different Perceptual Worlds (2 edition). Jessica Kingsley Publishers.

Bottema-Beutel, K., Kapp, S. K., Lester, J. N., Sasson, N. J., \& Hand, B. N. (2021). Avoiding Ableist Language: Suggestions for Autism Researchers. Autism in Adulthood, 3(1), 18-29. https://doi.org/ 10.1089/aut.2020.0014

Cage, E., Bird, G., \& Pellicano, L. (2016). 'I am who I am': Reputation concerns in adolescents on the autism spectrum. Research in Autism Spectrum Disorders, 25, 12-23. https://doi.org/10.1016/j.rasd. 2016.01.010

Davidson, J. (2008). Autistic culture online: virtual communication and cultural expression on the spectrum. Social \& Cultural Geography, 9(7), 791-806. https://doi.org/10.1080/14649360802382586

de Vries, B. (2021). Autism and the Right to a Hypersensitivity-Friendly Workspace. Public Health Ethics, phab021. https://doi.org/10.1093/phe/phab021

Dinh-Le, C., Chuang, R., Chokshi, S., \& Mann, D. (2019). Wearable Health Technology and Electronic Health Record Integration: Scoping Review and Future Directions. JMIR MHealth and UHealth, 7(9), e12861. https://doi.org/10.2196/12861

Gernsbacher, M. A., Stevenson, J. L., \& Dern, S. (2020). Autistic People Do Enhance Their Selves. Social Psychological and Personality Science, 11(5), 605-615. https://doi.org/10.1177/1948550619865057

Grandin, T. (2009). Thinking in Pictures. Bloomsbury Publishing.

Grandin, T., \& Barron, S. (2005). The Unwritten Rules of Social Relationships (V. Zysk (Ed.)). Future Horizons.

Human Rights Committee. (2011). General comment No. 34, Freedoms of opinion and expression (art. 19 of the International Covenant on Civil and Political Rights).

Izuma, K., Matsumoto, K., Camerer, C. F., \& Adolphs, R. (2011). Insensitivity to social reputation in autism. Proceedings of the National Academy of Sciences of the United States of America, 108(42), 17302-17307. https://doi.org/10.1073/pnas.1107038108

Jaarsma, P., \& Welin, S. (2012). Autism as a Natural Human Variation: Reflections on the Claims of the Neurodiversity Movement. Health Care Analysis, 20(1), 20-30. https://doi.org/10.1007/ s10728-011-0169-9

Jaswal, V. K., \& Akhtar, N. (2019). Being versus appearing socially uninterested: Challenging assumptions about social motivation in autism. Behavioral and Brain Sciences, 42. https://doi.org/10.1017/ S0140525X18001826

Judy Endow's Culture of Autism Presentation. (2009, July 25). https://www.youtube.com/watch?v=hlO9j 8UuC-w\&ab_channel=TheAutismSociety 
Kenny, L., Hattersley, C., Molins, B., Buckley, C., Povey, C., \& Pellicano, E. (2016). Which terms should be used to describe autism? Perspectives from the UK autism community. Autism, 20(4), 442-462. https://doi.org/10.1177/1362361315588200

Kumar, S., Yogesan, K., Hudson, B., Tay-Kearney, M.-L., \& Constable, I. J. (2006). Emergency eye care in rural Australia: role of internet. Eye, 20(12), 1342-1344. https://doi.org/10.1038/sj.eye.6702104

Kymlicka, W. (1995). Multicultural Citizenship: A Liberal Theory of Minority Rights. Clarendon Press.

Mesibov, G. B., Shea, V., Schopler, E., Adams, L., Merkler, E., Burgess, S., Mosconi, M., Chapman, S. M., Tanner, C., \& Bourgondien, M. E. V. (2004). The Culture of Autism. In The Teacch Approach to Autism Spectrum Disorders (pp. 19-32). Springer. https://link.springer.com/chapter/https://doi.org/ 10.1007/978-0-306-48647-0_3

Orgad, L. (2015). The Cultural Defense of Nations: A Liberal Theory of Majority Rights. Oxford University Press. http://www.oxfordscholarship.com/view/https://doi.org/10.1093/acprof:oso/9780199668 687.001.0001/acprof-9780199668687

Ought: The Journal of Autistic Culture. (n.d.). Retrieved September 6, 2020, from https://scholarworks. gvsu.edu/ought/

Patten, A. (2011). Rethinking Culture: The Social Lineage Account. The American Political Science Review, 105(4), 735-749. JSTOR. https://doi.org/10.2307/23275350

Prince-Hughes, D. (2005). Songs of the Gorilla Nation: My Journey Through Autism (Reprint Auflage). Broadway Books.

Reglitz, M. (2020). The Human Right to Free Internet Access. Journal of Applied Philosophy, 37(2), 314-331. https://doi.org/10.1111/japp.12395

Scott, M., Jacob, A., Hendrie, D., Parsons, R., Girdler, S., Falkmer, T., \& Falkmer, M. (2017). Employers' perception of the costs and the benefits of hiring individuals with autism spectrum disorder in open employment in Australia. PLOS ONE, 12(5), e0177607. https://doi.org/10.1371/journal.pone. 0177607

Shaheed, F. (2010). Report of the Independent Expert in the Field of Cultural Rights, Farida Shaheed, submitted pursuant to resolution 10/23 of the Human Rights Council (A/HRC/14/36). United Nations. https://digitallibrary.un.org/record/680585

Singer, J. (1999). "Why can't you be normal for once in your life?" From a "problem with no name" to the emergence of a new category of difference (chapter 7). In J. Singer \& S. French (Eds.), Disability discourse: Vol. Disability, human rights, and society (pp. 59-67). Open University Press. https://www.dawsonera.com/guard/protected/dawson.jsp?name=https://shidp.glam.ac.uk/shibboleth \&dest=http://www.dawsonera.com/depp/reader/protected/external/AbstractView/S9780335231201

Solomon, C. (2020). Autism and Employment: Implications for Employers and Adults with ASD. Journal of Autism and Developmental Disorders, 50(11), 4209-4217. https://doi.org/10.1007/ s10803-020-04537-w

Stace, C. (2014). Autism and Asperger's Syndrome: Social identity perceptions associated with LexicoSemantic terminology. Autarchive Repository (Critical Journal of Interdisciplinary Autism Studies), 1(1), Article 1. http://www.larry-arnold.net/Autonomy/index.php/Autarchive/article/view/ARK1

Straus, J. (2013). Autism as Culture. In L. J. Davis (Ed.), The Disability Studies Reader (4 edition, pp. 460-484). Routledge.

UN Committee on Economic, Social and Cultural Rights. (2009). General comment no. 21, Right of everyone to take part in cultural life (art. 15, para. Ia of the Covenant on Economic, Social and Cultural Rights) (E/C.12/GC/21).

Van Hoorn, J., Van Dijk, E., Crone, E. A., Stockmann, L., \& Rieffe, C. (2017). Peers Influence Prosocial Behavior in Adolescent Males with Autism Spectrum Disorders. Journal of Autism and Developmental Disorders, 47(7), 2225-2237. https://doi.org/10.1007/s10803-017-3143-Z

Yafai, A.-F., Verrier, D., \& Reidy, L. (2014). Social conformity and autism spectrum disorder: a childfriendly take on a classic study. Autism: The International Journal of Research and Practice, 18(8), 1007-1013. https://doi.org/10.1177/1362361313508023

Publisher's Note Springer Nature remains neutral with regard to jurisdictional claims in published maps and institutional affiliations. 